$\xi=-1$

\title{
Modeling the water quality index and climate variables using an artificial neural network and non-linear regression
}

\author{
Sumayah Amal Al-Din Majeed ${ }^{1}$, , Layla Ali Mohammed Saleh ${ }^{1}$, Gafel Kareem Aswed ${ }^{1}$ \\ ${ }^{I}$ Civil Engineering Department, University of Karbala \\ *Corresponding author E-mail: eng.sumayah@gmail.com
}

\begin{abstract}
This study aims to investigate the relationship between the water quality index (WQI) for irrigation purposes and four independent climate variables. Our case study was conducted on the Euphrates River within Karbala city, Iraq over the period between 2008 to 2016. The Bhar-gava WQI was calculated using nine physicochemical parameters, the electrical conductivity (EC), total dissolved solids, turbidity, $\mathrm{pH}$, and calcium, magnesium, sodium, chloride and sulfate levels. The Bhragava WQI classified the Euphrates river as generally "good". Artificial neural network (ANN) and non-linear regression models were developed and used to forecast the relationship between the WQI and four independent climate variables (temperature, relative humidity, and rainfall depth and sunshine duration). The nonlinear regression model was adopted to predicate the WQI because the coefficient of determination and minimum error value were better than those obtained with the ANN model. The non-linear model matched the calculated Bhargava WQI values and recorded meteorological data with a coefficient of determination $\left(\mathrm{R}^{2}\right)=78.2$ and standard error $=2.1$.
\end{abstract}

Keywords: Bhargava; Meteorological; Artificial Neural Network; Non-Linear Regression; Climate.

\section{Introduction}

Water resources such as rivers, streams and groundwater have an important role in the existence of life because water is essential for human, industrial, agricultural and domestic activities; this, in turn, depends on the classification of water quality. In recent decades, many factors have affected the quality and quantity of water, such as the increase in the human population, industrialization, civilization and impact of climate change, which further effect the problems associated with environmental pollution.

Changes in the climate conditions are mainly influenced by the hydrological cycle and this affects the quality of surface water. Changes in the water temperature, precipitation patterns and evaporation as well as extreme conditions, such as heavy rainfall, drought and flooding, lead to seasonal and temporal changes in the water quality and can cause various types of water pollution, such as nutrients, sediments, dissolved organic carbon, pesticides, pathogens and salt [1].

Increasing air temperature leads to an increase in the water temperature and evaporation, which will affect the biological and chemical properties of water resources by changing the mixing patterns and increasing the thermal stability, which can result in lower oxygen concentrations and a higher release of phosphorus from sediments i.e. the problems of water pollution, will increase [2]. In addition, heavy rainfall will cause a higher amount of total suspended solids (turbidity) in surface water due to soil erosion, which will give rise to pollution and thus lead to the deterioration in water quality. As the fluvial erosion process increases, the adsorbed pollutants, such as heavy metals and phosphorus, are mobilized [3]. In extreme conditions, flooding can lead to the pollution of water sources from solid waste and wastewater. In periods of drought, the low water flow reduces the dilution of contaminants and the pollution in the residual water sources is increased.
Many techniques have been used to determine the quality of water and the most general, simple and widely used method is the water quality index (WQI). The WQI method is a mathematical tool that combines various biological, physical and chemical parameters in a water sample obtained at a certain time and location. It is a dimensionless single number, which explains the degree of pollution [4].

The complex and difficult relationship between climatic factors and the water quality index has forced researchers to adopt an appropriate technique to represent this relationship. Artificial intelligence is widely applied in the field of water resources and used to develop the non-linear-environmental relationships. An artificial neural network system (ANN), as a kind of artificial intelligence, attempts to simulate the function of the nervous system and human brain [5] [6].

The impact of climatic conditions on water quality has attracted the attention of many researchers. Hafizan et al. [7] have developed two ANN models used to estimate the water quality index for the Langat River in Malaysia. The independent parameters studied were the biochemical oxygen demand, dissolved oxygen, ammonia nitrate, suspended solids, chemical oxygen demand and $\mathrm{pH}$. The correlation coefficient was 0.92 , while this factor became 0.91 upon removing the $\mathrm{pH}$ and chemical oxygen demand as input variables. The results indicate that the ANN model can estimate the WQI with suitable accuracy without these two independent parameters. Holmberg et al. [8] have attempted to estimate the total future concentration of organic carbon, phosphorus and nitrogen for three water streams in Finland using ANN models. The independent variables studied were the air temperature, run-off and precipitation as well as the characteristics of the catchment area. The network gave good results when compared with the alternative methods used to study the water quality of streams. Park et al. [9] studied the effects of climate change on the surface water quality and watershed biogeochemical processes over four 
years along the mountainous watersheds of Northeast Asia, which supply drinking water for a large number of people. The study indicated that the spatially variable patterns of summer precipitation or snow related to the regional climate change across this area have important impacts on the surface water quality and biogeochemical processes of the watershed and were related to acid deposition, the local topography or changes in land use. Sallam and Elsayed [10] measured the real-time water quality data obtained from monitoring stations in Lake Manzala and the water quality parameters were statistically analyzed. The analysis aimed to measure the seasonal and regional changes in relation to the variations in relative humidity and air temperature. Using Data Fit software simple formulas were elaborated to predict selected water quality parameters including the turbidity, $\mathrm{pH}$, electrical conductivity (EC), total dissolved solids (TDS), dissolved oxygen (DO), and chlorophyll as a function of the relative humidity, air temperature, and the quality and quantity of drainage water discharged into the lake. It was found there was an empirically positive relationship between the air temperature and relative humidity with the $\mathrm{pH}, \mathrm{EC}$ and TDS; a negative relationship was observed with the DO. There was no significant effect on the other two parameters of turbidity and chlorophyll. Hassan et al. [11] used the water storm management model (SWMM) to study the effects of climate variation on the storm drainage networks of Karbala city, Iraq. The system was developed for 2 years return, $9.6 \mathrm{~mm} / \mathrm{h}$ precipitation intensity and 60 minutes duration. The results showed that there was a deficit in the network capacity upon the increased flooding experienced in the region due to climate change. The study claimed that many of the networks needed to be redesigned to increase their capacity and reliability. The design density of the system was appropriate when there was no sewage discharged into the system. However, the amount of sewage that is currently discharged into the system has decreased the systems discharge capacity because sediments obstruct on the pipework. This has increased the time of flooding nearly two-fold when compared to the system with no sewage.

This paper explores the relationship between climate change factors and the WQI obtained for the Euphrates river within Karbala City over the period between 2008 and 2016 using ANN and nonlinear multi-regression models.

\section{Methodology}

\subsection{Case study}

The Euphrates river is the longest river in Southwest Asia; it is 1,740 miles $(2,800 \mathrm{~km})$ long. The river rises in Turkey and flows in a Southeast direction across Syria and through Iraq. The Euphrates basin covers about $440,000 \mathrm{~km}^{2}$ of which $22 \%$ in Syria, $28 \%$ in Turkey and $47 \%$ is in Iraq, and. Most of the Euphrates stream-flow originates from precipitation in the Armenian highlands. In Syria, the Balikh, Khabour and Sajur rivers and some intermittent streams contribute water to the Euphrates river; their contributions depend on the amount of precipitation, its intensity, and on the water use and drainage in upstream irrigation areas. In Iraq, there are no major surface water contributions to the Euphrates river except for the rare run-off that generated by heavy storms Water use of the Euphrates River in Syria, Iraq, and Turkey is focused on hydropower, irrigation and drinking water. Irrigation consumes the largest portion of water (more than 70\%) so the quality of the Euphrates river has become a serious problem and the agricultural drainage flows causing in salinity problems that make the situation become worse along the river course. In addition, the dispose of untreated sewage into the Euphrates River and its tributaries contribute in more pollution of water. The highly climate change resulting in variable availability of water. Under the existing management of water, as witnessed in recent events dryness of the basin is a main natural danger that affects the water supplies.
The middle (section) of the Euphrates river in Iraq within the Karbala Province was selected as our case study. The Euphrates river is divided into three tributaries in the Karbala province, namely the Bani-Hassan river, the Al-Husseiniya river and the Shatt AlHindia river. There are several sub-branches for each river. Ten stations were selected on the main and subsidiary branches of the Euphrates river, which are shown in Figure 1.

In order to evaluate the water quality index of the Euphrates river for irrigation purposes, the monthly raw water analysis results for the selected stations were obtained from the Water Directorate for Karbala Governate. The analysis results were for the period between January 2008 and December 2016, and involved the following parameters: EC, TDS, turbidity, $\mathrm{pH}$, cations (calcium, magnesium and sodium) and anions (chloride and sulfate).

The temperature, relative humidity, rainfall depth and sunshine duration were the climate variables considered in this research and were recorded at the Karbala meteorological station during the period of study. The statistical analysis results for the climate variables over the period of study (2008-2016) are shown in Table 1 .

\subsection{Determination of the WQI}

The WQI is a composite arithmetical tool indicator, which transforms multiple parameters of water quality into a single cumulative value, which expresses a specific level of water quality while eliminating the subjective assessments of this quality. The WQI is a simple, understandable management tool for managers and the public, which can be used to assess water quality information, the possibility of its particular use and provides an idea of the degree of pollution due to human activity based on the defined criteria [12 - 16]. The WQI technique includes three main steps: (1) The measurement of the water quality parameters, (2) the conversion of the measured parameter values into a "sub-index" rating and (3) the aggregation of the sub-index values for each parameter to determine the WQI value [17].

There are several indices used to evaluate the water quality based on various chemical, physical and biological parameters, which include the Canadian Council of Ministers of Environment (CCMEWQI), Oregon (OWQI), National Sanitation Foundation (NSFWQI), British Columbia (BCWQI), Overall Index of Pollution (OIP), Bhargava method and Smith's index. These WQI's differ from each other based on the sub-index rating method, the method used to statistically aggregate the parameter values and the interpretation of the results.

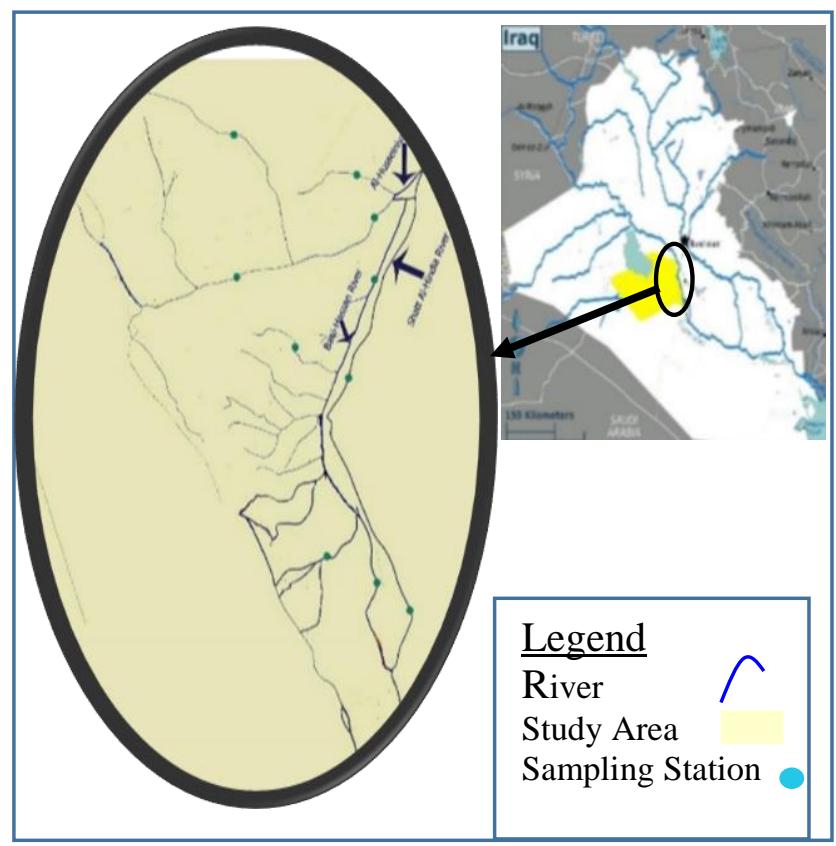


Fig. 1: The Geographical Location of the Study Area Relative to Iraq and Karbala Province.

Table 1: Statistical Analysis of the Climate Variables for the Period 2008-2016

\begin{tabular}{|c|c|c|c|c|c|c|c|c|c|c|c|c|c|c|c|c|}
\hline Year & \multicolumn{4}{|c|}{ Sunshine duration (h) } & \multicolumn{4}{|c|}{ Max. Temp. $\left({ }^{\circ} \mathrm{C}\right)$} & \multicolumn{4}{|c|}{ Relative humidity (\%) } & \multicolumn{3}{|c|}{ Rainfall (mm) } & \\
\hline & Mean & Max. & Min & $\begin{array}{l}\text { Std. } \\
\text { dev. }\end{array}$ & Mean & Max. & & $\begin{array}{l}\text { Std. } \\
\text { dev. }\end{array}$ & Mean & & & $\begin{array}{l}\text { Std. } \\
\text { dev. }\end{array}$ & Mean & & $\begin{array}{l}\mathrm{Mi} \\
\mathrm{n} .\end{array}$ & $\begin{array}{l}\text { Std. } \\
\text { dev. }\end{array}$ \\
\hline 2008 & 7.59 & 10.2 & 5.33 & 1.56 & 31.4 & 45.5 & 12.0 & 11.18 & 0.43 & 0.68 & 0.22 & 0.16 & 6.33 & 20.4 & 0.0 & 7.54 \\
\hline 2009 & 7.49 & 9.86 & 5.28 & 1.47 & 31.7 & 44.5 & 16.7 & 9.94 & 0.46 & 0.73 & 0.31 & 0.14 & 2.59 & 8.10 & 0.0 & 2.98 \\
\hline 2010 & 8.42 & 10.6 & 5.44 & 1.79 & 33.8 & 47.4 & 21.2 & 9.82 & 0.44 & 0.63 & 0.24 & 0.13 & 7.04 & 26.1 & 0.0 & 10.1 \\
\hline 2011 & 8.69 & 11.1 & 5.81 & 1.63 & 31.1 & 45.5 & 16.0 & 10.97 & 0.44 & 0.77 & 0.25 & 0.16 & 8.18 & 31.3 & 0.0 & 11.5 \\
\hline 2012 & 8.05 & 11.2 & 6.03 & 2.04 & 32.0 & 46.0 & 17.7 & 10.83 & 0.44 & 0.72 & 0.21 & 0.18 & 6.55 & 44.9 & 0.0 & 13.4 \\
\hline 2013 & 8.58 & 11.4 & 5.10 & 2.12 & 30.91 & 44.1 & 16.4 & 10.09 & 0.47 & 0.82 & 0.23 & 0.20 & 15.5 & 119.3 & 0.0 & 35.5 \\
\hline 2015 & 8.53 & 11.5 & 5.90 & 2.28 & 32.5 & 46.2 & 17.5 & 10.95 & 0.43 & 0.72 & 0.23 & 0.18 & 9.91 & 32.40 & 0.0 & 13.8 \\
\hline 2016 & 8.87 & 11.5 & 5.56 & 1.83 & 32.5 & 47.0 & 16.5 & 10.95 & 0.39 & 0.64 & 0.23 & 0.15 & 14.7 & 105.5 & 0.0 & 30.6 \\
\hline
\end{tabular}

In this study, the Bhargava method was adopted because it is prevalent in the evaluation of water quality in many countries and its simplicity for handling the relative parameters of water quality for various water uses. In this technique, the sensitivity curves are used to give the weight of each parameter, which is a function of its relative importance to the water quality for a specific use. The weight values range from zero to one. The results are accumulated using the geometric mean to achieve the WQI. The simplified model used to calculate the WQI is given by equation (1):

$$
W Q I=\left[\pi_{i=1}^{n} f_{i}\left(p_{i}\right)\right]^{1 / n} \times 100
$$

Where $\mathrm{n}$ is the number of water quality parameters and $\mathrm{f}_{\mathrm{i}}\left(\mathrm{p}_{\mathrm{i}}\right)$ is the sensitivity function of the $i^{\text {th }}$ parameter, which considers the effect of the parameter weight for a certain activity [18]. The WQI derived from geometric mean formula is used to classify water into five groups, as shown in Table 2 . The parameter weight is based on the sensitivity function curve and its value varies from zero to 1.The sensitivity function curves for irrigation purposes are shown in Figure 2. The index was applied to the raw water quality data obtained from the Euphrates river at Karbala, Iraq.

Table 2: Water Quality Classification According to the Bhargava Method [18]

\begin{tabular}{lll}
\hline Class & WQI & \\
\hline & Value & Quality \\
I & $100-90$ & Excellent \\
II & $89-65$ & Good \\
III & $64-35$ & Acceptable \\
IV & $34-11$ & Polluted \\
V & $<10$ & Severely polluted \\
\hline
\end{tabular}

\subsection{The artificial neural networks (ANNs) model}

ANNs, which are a type of artificial intelligence, try to simulate the biological structure of the human brain and nervous system. They are mainly used for complex estimation problems when the relationship between the variables cannot be expressed using a simple mathematical relationship [19]. The most common structure of an ANN consists of input, hidden and output layers. These layers are connected by neurons to form a parallel-distributed processing system where each node produces a non-linear function of its input. Both the layers of the output and input interact with the outside world. Any layer of neurons between the input and the output layers, hence hidden from the outside world, is called a hidden layer. A connection is a single line of communication that goes from the sending neuron to another receiving neuron [20], [21]. The composition of an ANN is illustrated in Figure 3. it is a schematic of a typical neurons variously called processing elements (PEs), or nodes. In the prior layer, the input from each node $\left(\mathrm{x}_{\mathrm{i}}\right)$ is multiplied by the modified connection weight $\left(\mathrm{w}_{\mathrm{ij}}\right)$ of the node and the weighted input signals are determined. A sill value $\left(\theta_{\mathrm{j}}\right)$ can be added as a bias. This joint input $\left(\mathrm{I}_{\mathrm{j}}\right)$ then passed through a transfer function to produce the output of the PE $\left(\mathrm{y}_{\mathrm{j}}\right)$. In the next layer the output of one PE provides the input to the PEs. This process is summarized in equations (2) and (3) [22], [23].
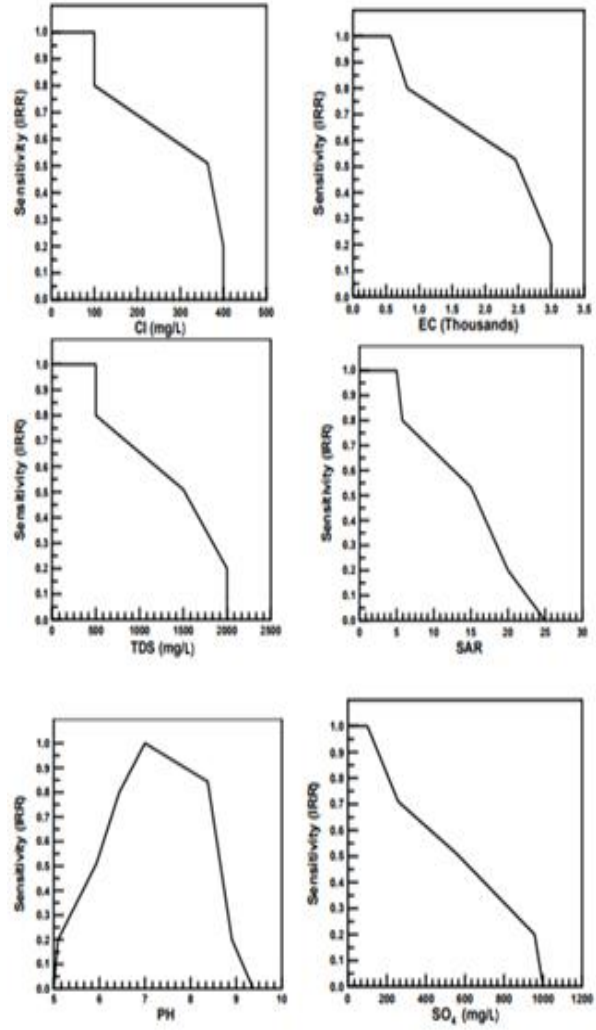

Fig. 2: The Sensitivity Function Curves According to Bhargava for Irrigation Purposes [14].

$\mathbf{I}_{\mathbf{j}}=\sum \mathbf{W}_{\mathbf{i j}} \mathbf{X}_{\mathbf{i}}+\boldsymbol{\theta}_{\mathbf{j}}$

$y_{i}=\mathrm{f}\left(I_{j}\right)=w \operatorname{Tanh}\left[\sum_{i=0}^{n} W_{i j} X_{i}\right]+\theta_{j}$

Where $I_{j}$ is the activation level of node $j, W_{i j}$ is the connection weight between nodes $i$ and $j, w$ is the connection weight of the output node, $X_{i}$ is the input from node $i(i=0,1,2, .),. \theta_{j}$ is the bias or threshold for node $j, y_{j}$ is the output of node $j$ and $f\left(I_{j}\right)$ is the transfer function.

The information spread in the ANN starts from the input layer where the input of data are presented. When submitting the training data set, the network modifies its weights. A learning rule is used to find a set of weights that has the minimum possible error. This process is called the training or learning phase. A set of independent testing is used to validate the performance of the successfully trained model [22]. 


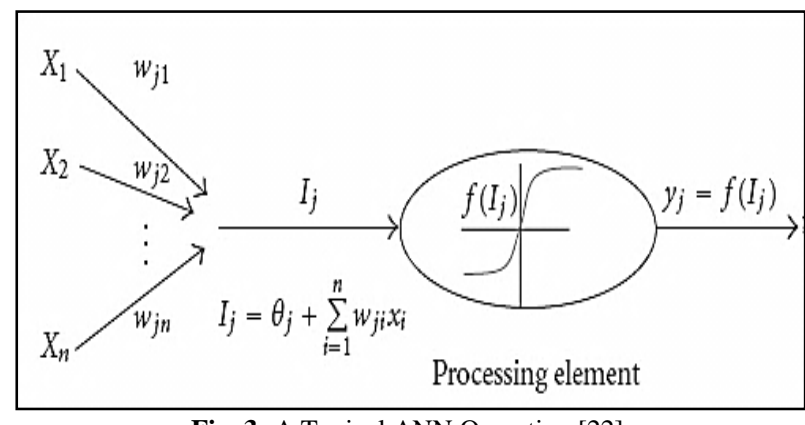

Fig. 3: A Typical ANN Operation [22].

\section{Results and discussion}

\subsection{Water quality index}

The statistical results of the WQI analysis over the period between 2008 and 2016 are illustrated in Table 3.

Table 3: Statistical Analysis of the WQI Results

\begin{tabular}{|c|c|c|c|c|}
\hline Year & Month & Statistic & WQI value & Class \\
\hline \multirow[t]{4}{*}{2008} & DEC. & Max. & 79 & II \\
\hline & JUN. & Min. & 68 & \\
\hline & & Mean & 72 & \\
\hline & & Std. Dev. & 3.2 & \\
\hline \multirow[t]{4}{*}{2009} & OCT. & Max. & 92 & I to II \\
\hline & FEB. & Min. & 76 & \\
\hline & & Mean & 83 & \\
\hline & & Std. Dev. & 5.2 & \\
\hline \multirow[t]{4}{*}{2010} & JUL. & Max. & 87 & II \\
\hline & OCT. & Min. & 77 & \\
\hline & & Mean & 82 & \\
\hline & & Std. Dev. & 3.2 & \\
\hline \multirow[t]{4}{*}{2011} & MAR & Max. & 80 & II \\
\hline & JUN. & Min. & 70 & \\
\hline & & Mean & 76 & \\
\hline & & Std. Dev. & 3.0 & \\
\hline \multirow[t]{4}{*}{2012} & JAN. & Max. & 77 & II \\
\hline & MAY & Min. & 65 & \\
\hline & & Mean & 72 & \\
\hline & & Std. Dev. & 4.4 & \\
\hline \multirow[t]{4}{*}{2014} & JAN. & Max. & 80 & II \\
\hline & AUG. & Min. & 71 & \\
\hline & & Mean & 75 & \\
\hline & & Std. Dev. & 2.8 & \\
\hline \multirow[t]{4}{*}{2015} & FEB. & Max. & 79 & II \\
\hline & AUG. & Min. & 69 & \\
\hline & & Mean & 74 & \\
\hline & & Std. Dev. & 3.6 & \\
\hline \multirow[t]{4}{*}{2016} & NOV. & Max. & 87 & II \\
\hline & JUN. & Min. & 77 & \\
\hline & & Mean & 82 & \\
\hline & & Std. Dev. & 2.7 & \\
\hline
\end{tabular}

The water quality of the Euphrates river is classified as "good" and belongs to class II except for the year 2009, in which varied from good to excellent.

By comparing the WQI results in Table 3 with the meteorological data illustrated in Table 2 the following results can be concluded for the year 2009:

1) The maximum calculated WQI was recorded in October 2009.

2) All the calculated statistical parameters for rainfall were the lowest.

3) All the calculated statistical parameters for the sunshine duration were the lowest.

4) The calculated statistical parameters for the max temperature were relatively low.

5) The calculated statistical parameters for the relative humidity were comparatively high.

As mentioned beforehand, low rainfall leads to the decreasing turbidity, sediment, nutrients and salt of water. A low sunshine duration and temperature in addition to a high relative humidity lead to decreasing evaporation and the pollution of water. As a result, the WQI will increase.

\subsection{The design of the ANN model}

In this study, a three-layered multi-layer perceptron (MLP) feedforward neural network architecture was used with five nodes in the hidden layer, as shown in Figure 4. The network was trained with $70 \%$ of the data and the remaining $30 \%$ of the data was used for testing. A batch training method was used with a gradient descent algorithm to train the network. Using the default parameters of the SPSS program in which the learning rate was 0.4 , the momentum term was 0.9 , the transfer function in the hidden layer was a hyperbolic tangent function and an identity function was used for the output layer, it was found that the network had the lowest prediction error for the testing set, which was 0.841 . The coefficient of determination $\left(\mathrm{R}^{2}\right)$ was found to be $53.3 \%$ and the standard error was 2.271. The connection weights and threshold (Bias) levels are summarized in Table 4.

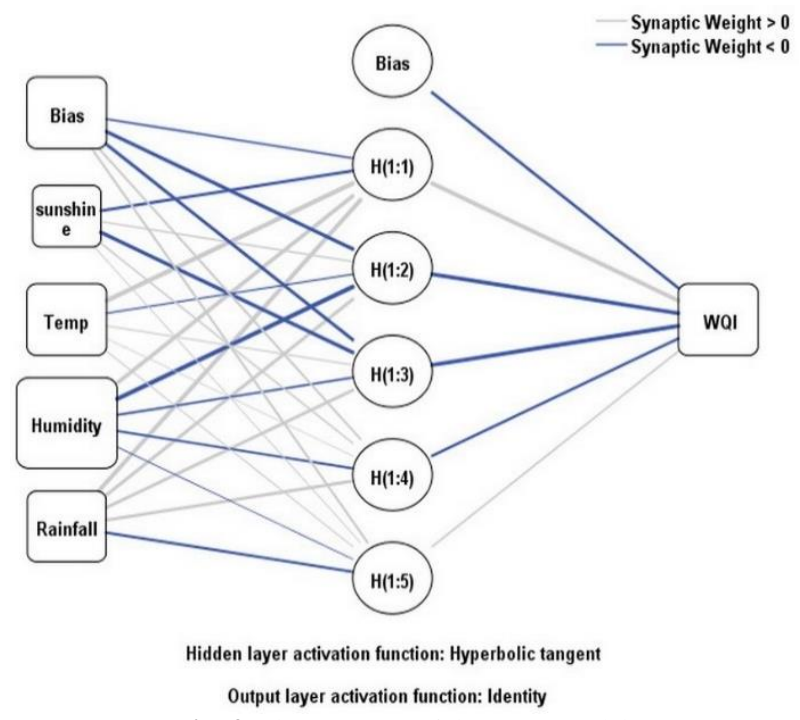

Fig. 4: The Structure of the ANN Model.

Table 4: Weights and Threshold Levels for the ANN Model

\begin{tabular}{lllllll}
\hline Input layer & \multicolumn{6}{l}{ Hidden layer } \\
& $(1: 1)$ & $(1: 2)$ & $(1: 3)$ & $(1: 4)$ & $(1: 5)$ & \\
Bias & -0.17 & -0.80 & -0.72 & 0.33 & 0.39 & \\
Sun. & -0.59 & 0.16 & -0.97 & 0.17 & 0.03 & \\
Tem. & 2.41 & -0.09 & 0.08 & 0.001 & 0.07 & \\
Hum. & 1.20 & -1.41 & -0.29 & -0.30 & -0.004 & \\
Rain. & 1.83 & 0.80 & 0.67 & 0.63 & -0.46 & \\
Output layer (WQI) & Hidden layer & & & & \\
& Bias & $(1: 1)$ & $(1: 2)$ & $(1: 3)$ & $(1: 4)$ & $(1: 5)$ \\
& -0.61 & 1.35 & -1.06 & -1.08 & -0.49 & 0.22 \\
\hline
\end{tabular}

\subsection{The development of the non-linear regression model}

Eleven powerful mathematical models were tested to forecast the relationship between the Bhargava WQI and each of the independent variable for 108 cases using the SPSS program (version 23). These models were, linear, quadratic, Quebec, exponential, logarithmic, power, inverse, S-curve, compound, growth and logistic. Table 5 illustrates the test statistics of the best-developed models used for the variables. Summing up the effect of each variable in one non-linear equation and recalculating the coefficient values to the new one, the final model equation had the following general form:

$$
\text { WQI }=b_{0}+b_{1} V_{1}+b_{2} V_{1}^{2}+b_{3}+b_{4} V_{2}+b_{5} V_{2}^{2}+b_{6} V_{2}^{3}+e^{b_{7}+\left(b_{8} / V_{3}\right)}+b_{9}+b_{10} V_{4}+b_{11} V_{4}^{2}
$$

where $\mathrm{V}_{1}, \mathrm{~V}_{2}, \mathrm{~V}_{3}$ and $\mathrm{V}_{4}$ are the sunshine, temperature, humidity and rainfall variables, respectively. The regression constants are $b_{0}$, $b_{1}, b_{2}$ to $b_{11}$. Table 6 illustrates the regression constants of the 
model. The developed model has $\mathrm{R}^{2}=59.8 \%$ with a mean square error $=4.945$.

Table 5: The Statistical Test of the Models Studied.

\begin{tabular}{llllll}
\hline Model & $\begin{array}{l}\text { Independent } \\
\text { variable }\end{array}$ & $\mathrm{R}$ & $\mathrm{R}^{2}$ & $\begin{array}{l}\text { Adjusted } \\
\mathrm{R}^{2}\end{array}$ & $\begin{array}{l}\text { Std. } \\
\text { Error }\end{array}$ \\
\hline Quadratic & Sunshine $\left(\mathrm{V}_{1}\right)$ & 0.265 & 0.070 & 0.052 & 3.22 \\
Cubic & Temp. $\left(\mathrm{V}_{2}\right)$ & 0.280 & 0.078 & 0.052 & 3.221 \\
S-curve & Humidity $\left(\mathrm{V}_{3}\right)$ & 0.295 & 0.087 & 0.079 & 0.041 \\
Cubic & Rainfall $\left(\mathrm{V}_{4}\right)$ & 0.279 & 0.078 & 0.060 & 3.207 \\
\hline
\end{tabular}

Table 6: The Estimated Parameters

\begin{tabular}{ll} 
& Table 6: The Estimated Parameters \\
\hline Parameter & Estimate \\
\hline $\mathrm{b}_{0}$ & 127.0081 \\
$\mathrm{~b}_{1}$ & 5.768 \\
$\mathrm{~b}_{2}$ & -0.3586 \\
$\mathrm{~b}_{3}$ & 37.3051 \\
$\mathrm{~b}_{4}$ & 3.7293 \\
$\mathrm{~b}_{5}$ & -0.1253 \\
$\mathrm{~b}_{6}$ & 0.001 \\
$\mathrm{~b}_{7}$ & 3.9263 \\
$\mathrm{~b}_{8}$ & -0.188 \\
\hline
\end{tabular}

\subsection{Validation of the non-linear model}

The statistical analysis results of the non-linear and ANN models indicate that non-linear regression model gave a better coefficient of determination and less error than the ANN model. As a result, model equation (4) can be adopted to predicate the Bhargava WQI for the limited conditions used in this study. In order to test the validity (accuracy) of the developed model, seven cases were randomly set aside and used for this purpose, which was about $7 \%$ of the total number of cases. Linear regression analysis in the SPSS program was performed between the observed and predicted values of the WQI. The seven predicted WQI values were plotted against the seven actual values used in the validation data set, as shown in Figure 5. The $\mathrm{R}^{2}$ values along with the standard error are shown in Table 7, and indicate that the most variability in the WQI can be explained by the terms in the model. Therefore, it can be concluded that this model shows a good correspond with the actual measurements.

Table 7: The Residuals of the ANOVA Process

\begin{tabular}{|c|c|c|c|c|}
\hline Model & $\mathrm{R}$ & R Square & Adj. R Square & Std. Err. Est. \\
\hline 1 & 0.885 & 0.782 & 0.739 & 2.10085 \\
\hline
\end{tabular}

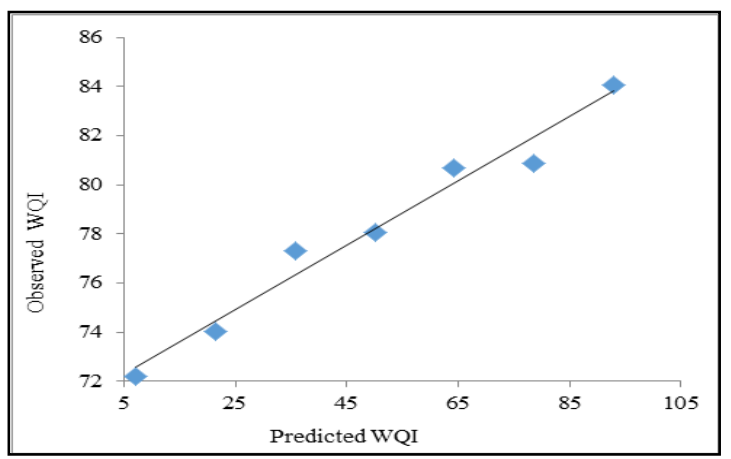

Fig. 5: A Scatter Plot of the Predicted and Actual Values Obtained for the WQI

\section{Conclusion}

The relationship between the climate variables and WQI obtained for the Euphrates River over the period between 2008 and 2016 was investigated using ANN and non-linear multi-regression models. The results showed that the non-linear model matches the calculated Bhargava WQI and recorded climate data with $\mathrm{R}^{2}=$ 78.2 and standard error $=2.1$.

\section{References}

[1] Bates BC, Kundzewicz ZW, Wu S \& Palutik JP (2008), Climate Change and Water. Technical Paper of the Intergovernmental Panel on Climate Change. IPCC Secretariat, Genevap, 210.

[2] Nicholls KH (1999), Effects of temperature and other factors on summer phosphorus in the inner Bay of Quinte, Lake Ontario: Implications for climate warming. Journal of Great Lakes Res. 25 250-262. https://doi.org/10.1016/S0380-1330(99)70734-3.

[3] Mimikou MA, Baltas E, Varanou E\& Pantazis K (2000), Regional impacts of climate change on water resources quantity and quality indicators. Journal of Hydrology 234, 95-109. https://doi.org/10.1016/S0022-1694(00)00244-4.

[4] Tyagi S, Sharma B, Singh P\& Dobhal R (2013), Water quality assessment in terms of water quality index. American journal of water resources $3,34-38$

[5] Jain A, Prasad \& Indurthy SK (2004), Closure of comparative analysis of event-based rainfall-runoff modeling techniquesDeterministic, statistical and artificial neural networks. Journal of Hydrologic Eng. 9, 551-553. https://doi.org/10.1061/(ASCE)10840699(2004)9:6(551).

[6] Wu CL, Chau KW\&Li YS (2009), Methods to improve neural network performance in daily flows prediction. Journal of Hydrology 372, 80-93. https://doi.org/10.1016/j.jhydrol.2009.03.038.

[7] Juahir H, Zain SM, Toriman ME, Mokhtar M\& Man HC (2004), Application of artificial neural network models for predicting water quality index. Malaysian Journal of Civil Engineering 16, 42-55.

[8] Holmberg M, Forsius M, Starr M\& Huttunen M(2006), An application of artificial neural networks to carbon, nitrogen and phosphorus concentrations in three boreal streams and impacts of climate change. Journal of Ecological Modelling195, 51-60. https://doi.org/10.1016/j.ecolmodel.2005.11.009.

[9] Park JH, Duan L, Kim B, Mitchell MJ\& Shibata H (2010), Potential effects of climate change and variability on watershed biogeochemical processes and water quality in Northeast Asia. Journal of Environment International 36, 212-225. https://doi.org/10.1016/j.envint.2009.10.008.

[10] Sallam GA\& Elsayed EA (2015), Estimating relations between temperatures, relative humidity as in depended variables and selected water quality parameters in Lake Manzala, Egypt. Journal of Natural Resources and Development 5, $76 \quad 87$ https://doi.org/10.5027/jnrd.v5i0.11.

[11] Hassan WH, Nile BK \& Al-Masody BA (2017), Climate change effect on storm drainage networks by storm water management model. Journal of Environmental Engineering Research 22, 393400. https://doi.org/10.4491/eer.2017.036.

[12] Walsh P \&Wheeler W. Water (2013), quality index aggregation and cost benefit analysis. Journal of Benefit-Cost Anal. Four, 81-106.

[13] Jahad UA (2014), Evaluation water quality index for irrigation in the north of Hilla city by using the Canadian and Bhargava methods Journal of Babylon University 2,346-353.

[14] Stambuk-Giljanović N (2003), Comparison of Dalmatian water evaluation indices. Journal of Water Environ. Res.75, 388-405. https://doi.org/10.2175/106143003X141196.

[15] Avvannavar SM \&Shrihari S (2008), Evaluation of water quality index for drinking purposes for river Netravathi, Mangalore, South India. Journal of Environmental Monitoring and Assessment 143,279-90. https://doi.org/10.1007/s10661-007-9977-7.

[16] Radwan M. (2005), Evaluation of different water quality parameters for the Nile River and the different drains. Ninth International Water Technology Conference, Sharm El-Sheikh, Egypt, 12931303.

[17] Katyal D (2011), Water quality indices used for surface water vulnerability assessment. International Journal of Environmental Science 2,154-173.

[18] Bhargava DS, Saxena BS\& Dewakar RW (1998), a study of geo pollutants in the Godavari River in India. Asian Journal of Environmental $12,36-59$.

[19] Khaled DZ, Frayyeh DQ\& Aswed GK (2014), modeling final costs of Iraqi public school projects using neural networks. International Journal of Civil Eng. Technol. 5, 42-54.

[20] Awodele O\& Jegede O (2009), neural networks and its application in engineering. Proceedings of Informing Science \& IT Education Conference, 83-95.

[21] Fadlalla a\& Lin CH (2001), an analysis of the applications of neural networks in finance. Interfaces Journal 31, 112-122. https://doi.org/10.1287/inte.31.4.112.9662.

[22] Shahin MA, Jaksa MB\& Maier HR (2009), recent advances and future challenges for artificial neural systems in geotechnical engi- 
neering applications. Journal Advances in Artificial Neural Systems, 1-9.

[23] Gerard D (2005), Neural Networks Methodology and Applications. Springer-Verlag Berlin Heidelberg, Germany ISBN-10 3-54022980-9. 